\begin{tabular}{|ccc|}
\hline & ANNALES INSTITUTI SLAVICI \\
& UnIVERSITATIS DEBRECENIENSIS & \\
SLAVICA XLVII & 2018 & DEBRECEN \\
\hline
\end{tabular}

Beáta GYÖRFI

\title{
О ПРОБЛЕМЕ НАЛИЧИЯ ЭКСПЛЕТИВНЫХ СУБЪЕКТОВ В РУССКОМ ЯЗЫКЕ
}

\section{On the Existence of Expletive Subjects in Russian}

According to traditional grammars, Russian does not contain expletive subjects. However, investigations in the generative framework suggest, that the pronoun эmo with certain predicates can be perceived as an expletive subject. The present article gives a short overview of previous investigations and aims at providing a unified analysis of constructions with - $O$ final adverbial predicates or with the verbs бывать and нравиться.

Keywords: expletive subject, эmo, adverbial predicates, unaccusatives, EPP

\section{о. Введение}

Согласно традиционным грамматикам [ШВЕДОВА 1980; ВАЛГИНА 1991/2003] русский язык представляет широкий диапазон субъектов ${ }^{1}$ По формальным критериям различаются номинативный, клаузальный (финитные или инфинитивные (Р) и фонетически пустой субъект. Однако работы в рамках генеративного синтаксиса упоминают, что в русском имеется и эксплетивный субъект, это:

(1) Это интересно.

(2) Это интересно, что данные соборы были связаны с революцией.

Данная статья представляет собой обобщение и уточнение применением современного генеративного аппарата имеющего исследования в данной области.

В первой части дается типологический обзор эксплетивных субъектов. Во второй части дается перечень конструкций, содержащих эксплетивный субъект. Рассматриваются результаты уже проведенных исследований. Поскольку они не предлагают единую трактовку разнообразных структур, предполагая наличия эксплетивного субъекта (явно выраженного или нулевого) в позиции SpecTP, предлагается объяснение разнообразных конструкций. В то же время решается вопрос о том, действительно можно ли предполагать эксплетивный субъект в русском.

1 Конечно набор подлежащих зависит от выбранного подхода изучения: Шведова с функциональной точки зрения упоминает существительные в именительном падеже, словосочетания с количественным значением и инфинитив. Валгина, применяя структурно- функциональный подход перечисляет существительные, местоименные-сучшествительные, любую субстантивизированную часть речи и словосочетания. 


\section{1. Типология эксплетивных субъектов}

Эксплетивами называются те синтаксические «вставные слова», которые не обладают собственным значением, а имеют лишь формальную функцию, поскольку они занимают определенную структурную позицию в предложении. Они не придают особое семантическое значение предложению а выполняют структурную или прагматическую роль. Несмотря на то, что эксплетивы проявляют функциональное разнообразие ${ }^{2}$, труды по синтаксису чаще всего занимаются эксплетивными субъектами.

Употребление эксплетивных субъектов предписано принципом расширенной проекции генеративной грамматики, который утверждает, что каждое предложение должно иметь субъект (в позиции SpecTP, SpecIP или SpecVP, в зависимости от типологических особенностей языка). Они встречаются во множестве языков и характеризуются многообразием. В зависимости от ЕРР свойств, в некоторых языках появление эксплетивных субъектов является обязательным, а в других факультативным. По формальным признакам различаются эксплицитно выраженные и фонетически пустые (pro) эксплетивные субъекты. На основе их синтаксических свойств различаем тематические эксплетивные субъекты, которые обладают тематической ролью и нетематические ${ }^{3}$. Также имеются экслетивные субъекты, которые вызывают согласование (1), и которые нет (2).

(3) It seems that you like pancakes.

(4) There are pancakes on the table.

Явно выраженные эксплетивы по типу структуры, в котором они встречаются, дальше разделяются на следующие подтипы [БИБЕРАУЕР 2012]:

1. эксплетивы с глаголами погоды: It is raining.

2. эксплетивы в презентационных предложениях: There arrived some yellow birds.

3. эксплетивы в экзистенциальных предложениях: There are pancakes on the table.

4/a при экстрапозиции: It is obvious that you like pancakes.

4/b при выделении: It seems that you like pancakes.

5. эксплетивы в безличных конструкциях: Der må ikke ryges. „Курить запрешается."'

2 В русском языке экслпетивами являются например вводные слова/выражения типа «на мой взгляд》, в венгерском указательное местоимение «ott» [ШурАни 2005].

3 Подлежащие выступающие с глаголами погоды являются тематическими эксплетивными субъектами, поскольку они принимают единственную тематическую роль предиката [+argumental]. [BIEBERAUER 2012]. 
По интерпретивному эффекту (interpretative effect) различаем презентационные эксплетивы, которые предопределяют наличие элемента, обозначающего новую информацию, и экстрапозициональные эксплетивы, которые ссылаются на определенный член структуры [БИБЕРАУЕР 2012].

На основе того, какие эксплетивы употребляются в языках, можно типологически распределить языки в три группы [BIBERAUER 2012]:

1. К первой группе относятся языки, которые содержат малочисленные эксплетивы, употребление которых представляется обязательным. Таким языком является гаитянский креольский.

2. Во второй группе языков встречаем только 1-2 эксплетива, которые являются факультативными. Примером служит финский язык.

3. Третья группа языков содержит разных типов эксплетивных местоимений, использование которых является обязательным. Сюда относится английский и континентальный скандинавский.

В следующем разделе рассмотрим, имеются ли эксплетивы в русском, а если да, то какими свойствами они обладают.

\section{2. Имеется ли эксплетивный субъект в русском?}

Вопрос о наличии эксплетивных субъектов в русском языке разделяет синтаксистов на два лагеря. Слюссар (2011) без особенного объяснения декларирует, что в русском нет фонетически явно выраженных эксплетивных субъектов. В то время, как Бейлин (2011), Френкс (1995) и Циммерлинг $(2009,2014)$ настаивают на существование эксплетивного субъекта это в русском. Данное положение по всей вероятности восходит к тому, что в первую очередь под эксплетивами понимаем обязательные элементы типа английского it, there или немецкого es. До сих пор не уделялось самостоятельное исследование проблеме существования эксплетива в русском языке. Данный вопрос изучался лишь как побочное явление в ходе других исследований.

Местоимение это в русском языке является новообразованием, поскольку оно возникло в следствии преобразования древнерусской системы указательных местоимений в XVIII. веке. Сначала это выполняло дейктическую функцию, а позже стал употребляться в застывшей форме единственного числа именительного падежа, среднего рода в функции референциального (анафорического или катафорического) местоимения.

(5) Это известно ему, Шахову, потому, что он в продолжении этого времени находился при г. Исправнике. (Из истории немецкого народа)

В современном языке это характеризуется функциональным разнообразием: оно выполняет роль указательного местоимения, анафорического местоимения или связки [ДЬЕРФИ 2016]. 
Особое внимание заслуживают конструкции, в которых это выступает с адвербиальными предикатами с финалью -о ${ }^{4}$. Данные структуры встречаются в следующей дистрибуции:

(6) Это трогательно.

(7) Мне это грустно.

(8) Это любопытно, что людьми мы становимся, когда наводнение.

(9) Любопытно, что в лесах Южной Америки молодые листья на деревьях редко имеют красноватый оттенок.

(10) Мне странно, что они не захотели узнать видение других сейлзхаусов.

(11) Что Макс шпион, это очевидно.

В примере (6) это выступает лишь с адвербиальным предикатом, в (7) с аргументом в дательном падеже, в (8) с СР, в (9) наряду с адвербиальным предикатом найдем только СР, в (10) аргумент в дательном падеже и СР. В (11) это расположено в постпозиции к СР, но перед адвербиальным предикатом.

Кроме вышеуказанных примеров, данные НКРЯ свидетельствуют о том, что местоимение это в подобной дистрибуции встречается и в конструкциях содержащих глагольный предикат «бывать» или «нравится»:

(12) Это бывает, что иногда женщины спокойнее мужчин - сказал Матвеев.

(13) Редко это бывает, что прилетают на Пасху ласточки.

(14) В России это бывает, что медведь возьмет арфу, да на арфе и сыграет отлично.

(15) Бывает, что в один день клуб меняет статус.

(16) Мне это нравится.

(17) Мне это нравится, что ты такой бес.

(18) Мне не нравится, что каждый огурец стоит один рубль пятнадцать копеек.

Как из вышеприведенных примеров видно, это при глаголе бывать подобно наречным предикатам выступает с СР дополнением (12), (13), (14), а в (15) имеется только СР дополнение без местоимения. Разница между конструкциями заключается в том, что наряду с «бывать» не встречаем конструкции без СР дополнения.

С глаголом «нравиться» однако находим дательный аргумент наряду с это (16), дательный аргумент, это и чтоСР (17), а в (18) это опущено.

Необходимо однако отметить, что это можно употреблять не со всеми побочными значениями «бывать». Апресян различает 5 побочных значений данного глагола: [АПРЕСЯН 2014, ПАДУЧЕВА 2015]. УПотребление это связано с значением «случаться, неоднократно иметь место». Падучева замечает, что в данном контексте субъектом глагола является некая ситуация.

Вышеприведенные структуры характеризуются разнообразием словопорядка. Это можно суммировать следующим образом:

4 Примеры взяты из Национального корпуса русского языка (далее НКРЯ). 
Структура конструкций содержащих это:

$\begin{array}{lcll} & \text { это } & \text { PredADV } & \\ & & \text { PredADV } & \\ \text { Dat } & \text { это } & \text { PredADV } & \\ & \text { это } & \text { PredADV } & \text { чтоCР } \\ & & \text { PredADV } & \text { чтоCР } \\ \text { Dat } & & \text { PredADV } & \text { чтоCР } \\ \text { чтоСР } & \text { это } & \text { PredADV } & \end{array}$

Структуры с глаголом бывать:

\begin{tabular}{|l|l|l|}
\hline это & бывает & чтоСР \\
\hline & бывает & чтоСР \\
\hline
\end{tabular}

Структуры с глаголом нравиться:

\begin{tabular}{|l|l|l|l|}
\hline Dat & это & нравится & чтоСР \\
\hline Dat & это & нравится & \\
\hline Dat & & нравится & чтоСР \\
\hline
\end{tabular}

Как видно из данных таблиц, в НКРЯ не находим примера для существования некоторых конструкций, (напр.: DAT+это+PredAdv+чтоCP, DAT+PredAdv, это+бывает, бывает, это+нравится+чтоСР).

\section{3. Можно ли считать это эксплетивным субъектом?}

Это безусловно является эксплетивным элементом, ведь оно не обладает собственной семантикой. Данный факт подтверждает, что местоимение может быть свободно опущено, т. е. оно не является обязательными членом упомянутых конструкций. Это - в противоположность немецкому и английским эксплетивам - не занимает определенную структурную позицию, оно встречается и препозитивно (8) и постпозитивно (11) относительно чтоСР.

Что касается формальных критериев субъектности, то это вызывает согласование в единственном числе, 3 лице, среднем роде. Однако местоимение это не удовлетворяет другие критерии субъектности, поскольку оно не вызывает контроль в деепричастных оборотах и не связывает анафоры [ЦИММЕРЛИНГ 2009: 13] .

С функциональной точки зрения, у это субъектов можно разграничить две функции: референциальную или коррелятивную ${ }^{6}$. В функции референциаль-

5 Даже подходящего контекста нельзя найти для таких примеров.

6 Циммерлинг называет неемфатический это субъект коррелятивным местоимением [ЦимМЕРЛИНГ 2009]. 
ного местоимения это отождествляет антецедент из контекста и всегда обязательно присутствует. В примере (19) это ссылает на содержания предыдущего предложения. Однако при адвербиальных предикатах и быввать, это коррелирует с чтоСР или при его отсутствии с окружающим IP (20).

(19) Я проходил стажировку в Бристоле, Англия. Но это было так давно!

(20) Первый муж. Это любопытно. Сколько же их у Танечки?

В следующем разделе рассмотрим подробнее конструкции с адвербиальными предикатами и раскрываем связь между членами конструкций.

\section{4. Истолкования конструкций с эксплетивом и СР дополнением}

Конструкции с эксплетивом и чтоСР дополнением являются особенностью русского синтаксиса, и имеются несколько трактовок этих оборотов. В данной части дается краткое изложение этих исследований. Их общей чертой является, что они все проводились в рамках генеративной методики.

\section{1. Теория цепочки (Chain analysis)}

В германских языках встречаются подобные к русской конструкции с это структуры, в которых определенные предикаты приписывающие наличия СР комплементов требуют и обязательного или факультативного появления эксплетивных субъектов. Такой конструкцией является например английский оборот с эксплетивным субъектом $i$.

(21) $\mathrm{It}_{\mathrm{i}}$ is surprising, [cP that John knows about you $]_{\mathrm{i}}$.

Согласно Хомскому [1981] эксплетив и соиндексированное с ним СР образуют цепочку: они составляют один совместный аргумент, который состоит из двух фонетически раздельных частей. Один член - СР - получает тематическую роль, другой член - эксплетив - падеж (case transmission).

Данный анализ применял для объяснения конструксий содержащих это и чтоСР Френкс [1995: 319]:

(22) (Это) приятно [ср что мы гуляем в парке].

(23) (*Это) приятно [ср PRO гулять в парке].

(24) (*Это) приятно [рр в парке].

Френкс сопоставляет русские и английские обороты. Он устанавливает, что русский эксплетив отличается от английских, поскольку в русском эксплетивное местоимение с адвербиальными предикатами употребляется только с финитными СР. ${ }^{7}$, и это может свободно пропускаться.

В английском структуры типа It is nice to walk in the park. и It is nice in the park. Приемлемы, однако их русские соответствия неправильны: * Это приятно гулять в парке. *Это приятно в парке. 
Возникает вопрос, как осуществляется приписка падежа внутри цепочки. Френкс предполагает, что русский не является языком pro-drop ${ }^{8,}$ то есть требует появления эксплицитно выраженных субъектов. Эксплетив получает номинатив для видимости на уровне логической формы (LF). В отсутствии эксплетива падеж приписывается чтоСР. Что касается проблемы пропущения это, Френкс полагает, что поскольку плеонастические элементы не обладают значением, на уровне фонетической формы (PF) их можно свободно пропускать [FRANKS 1995: 321].

Развитием генеративной грамматики вышеизложенная теория подвергалась критике: в поздних версиях теории уже не существует явление «передачи падежа», каждая NP должна овладеть самостоятельным падежом, а СР не могут его получить.

\section{2. Анализ Межевич}

Межевич предлагает альтернативное решение для трактовки это и СР [2004: 319]. Учитывая недостатки анализа Хомского она считает это не эксплетивным субъектом, а полагаясь на анализ еврейского местоимения ze, референциальным местоимением [ХАЗУТ 1994] ${ }^{9}$. Такой подход поднимает два вопроса: с одной стороны, надо снова уточнить отношение СР и это, с другой, надо определить антецедент это. Межевич полагает, что структуры содержащие поствербальный СР образуют две различные конструкции в зависимости от того, присутствует ли или опускается в них элемент это: в случае пропущения это адвербиальный предикат придает внутреннюю тематическую роль СР, которая становится обязательным аргументом. Если же это эксплицитно выражено, оно получает внешнюю тематическую роль от AGR (данная вершина обеспечивает согласование в 3 лице единственного числа), а придаточное предложение будет его перемещаемым направо адъюнктом (Right Dislocated Adjunct).

Что касается интерпретации это, Межевич полагает наличие структурного и также семантического антецедента. Роль структурного антецедента выполняет вершина AGR, которая обеспечивает ф признаки элемента это (3. л ед.ч., средний род). Поскольку AGR не является лексической вершиной, она не способна снабжать это с семантической референцией. Данной референции способствует соиндексированная с это СР.

Предлагаемый Межевич анализ является проблематичным с разных точек зрений: с одной стороны, адвербиальные предикаты с финалью -о не способны приписывать тету-роль. С другой стороны, это располагается слева от своего антецедента, то есть имеем дело с постцендентными СР. Межевич не предлагает единое толкование оборотов с чтоСР и без него. Вдобавок, предлагаемый анализ не учитывает разнообразие словопорядка в конструкциях (см. (8), (11)).

8 Согласно терминологии Френкса русский причисляется к [+OSP] (Overt Subject Parameter) языкам, то есть требует появления явно выраженного подлежащего.

9 Синтаксическая дистрибуция еврейского местоимения zе и русского это сходна: в некоторых конструкциях они могут быть свободно пропущены, и не встречаются с унаккузативными или пассивными предикатами. 


\section{3. Анализ Циммерлинга}

Циммерлинг изучает способы выражения субъектов в структурах с адвербиальными предикатами [ЦИММЕРлИНГ 2014]. В данной структуре разные элементы претендуют на роль субъекта: эксплетивный эmo ${ }^{10}$, дательный субъект и чтоСР субъект ${ }^{11}$.

(25) Это удивительно, что погода не испортилась.

(26) * Мне это удивительно, что погода не испортилась.

(27) Мне это удивительно.

(28) Что погода не испортилась, удивительно.

(29) Удивительно, что погода не испортилась.

(30) Мне удивительно, что погода не испортилась.

Изучая дистрибуцию конструкции Циммерлинг приходит к выводу, что это функционирует субъектом только в том случае, если структура не содержит ни дательного субъекта ни придаточного СР. Если дательного субъекта в конструкции нет, СР становится поверхностным субъектом и в препозитивной и в постпозитивной позиции. В этом случае это является лишь коррелятивным местоимением, которое отсылает к содержанию СР. Циммерлинг замечает, что это свободно чередуется с фонетически пустым субъектом pro [ЦиММЕРлИНГ 2009: 11], однако позже не возвращается к этой проблеме и ограничивается только способами выражения эксплицитных субъектов.

Анализ Циммерлинга написан использованием генеративного и функционального подхода, поэтому содержит ряд противоречий: например дательные аргументы у него воспринимаются как субъекты. Он не предлагает единый анализ структур содержащих это или СР и лишенных их.

\section{5. Современный генеративный анализ конструкций с эксплетивным это}

Как видно, выше изложенные трактовки сосредоточатся только на анализ конструкций с адвербиальными предикатами, не учитывая, что это подобным образом ведет себя с некоторыми глаголами. В данной части рассмотрим какое объяснение предлагает расширение фокуса анализа привлечением глагольных конструкций.

Как примеры показывают, эксплетивное это встречается с некоторой семантической группой адвербиальных предикатов на - $о$ и с определенным побочным значением глагола бывать глаголом нравиться. Данные предикаты обладают подобной структурой: выступают с чтоСР и с дательными аргументами (кроме бывать) Возникает вопрос, какая общая черта имеется в их аргументной структуре, ради которой они разрешают появление и опущение это.

Сначала надо уточнить роль чтоСР, то есть определить, является ли придаточное предложение субъектом конструкций.

10 Циммерлинг употребляет название семи-эксплетивный субъект.

11 Примеры взяты из Циммерлинга [ЦиммЕРлинг 2014: 270]. 
Циммерлинг предполагает, что придаточное с адвербиальными предикатами действительно можно считать внутренним аргументом конструкций. Что касается глаголов бывать и нравиться, они являются унаккузативными глаголами с внутренним аргументом, субъектом (и дательным аргументом в случае нравиться).

Подобно исследуемым предикатам появления финитного чтоСР требуют и некоторые пассивные глаголы. В этих конструкциях СР также выполняет роль субъекта. Однако, в этих конструкциях употребление это невозможно [СЛЮССАРь 2011].

(31) (*Это) написано [ср что рейс задерживается].

(32) (*Это) оказывается [ср что земля круглая].

Употребление это в данных структурах также оказывается неправильным (см. (27), (28)). Неверный характер этих примеров Слюссарь объясняет тем, что СР в них является внутренним подлежащим [СлЮССАРь 2011], и появление это наряду с ними невозможно, поскольку это было бы внешним субъектом.

Если это воспринимаем как эксплетивный субъект, он не является аргументом, ему не приписывается тета-роль, только выполняет формальную роль внешнего субъекта в позиции SpecTP.

Для решения проблемы свободного опущения это предполагаем наличие фонетически пустого, «тихого» эксплетива рro в структурах не содержащих это.

Введение пустого эксплетива происходит по аналогии трактовки экзистенциальных конструкций. Зохен [2002] на основе «гипотезы тихого эксплетива» (Silent Expletive Hypothesis) Перлмутэра и Мура [2002] предполагает наличие фонетически пустого субъекта в позиции Spec,TP:

(33) Меня pro тошнило.

(34) рro рассветало.

(35) На улице pro было холодно.

Данную гипотезу можно расширять и на структуры содержащие адвербиальные предикаты. Таким образов в тех конструкциях, которые не содержат это, предполагаем наличие фонетически нулевого эксплетивного pro.

(36) pro Интересно.

(37) pro не удивительно, что Лондон сохранил первую строку в рейтинге.

(38) Мне pro странно, что в некоторых школах решение о форме.

(39) pro бывает, что на репетициях они просто выполняют указания режиссеров.

Введение фонетически пустого подлежащего делает возможным единообразное толкование структур с разными аргументами и разнообразным словопорядком.

Дательный комплемент адвербиальных предикатов и нравиться расположен в позиции выше SpecTP, например в SpecTopP. 


\section{6. Итоги}

Как изучение вышеприведенных конструкций показывают, в русском существуют два эксплетивных субъекта: это и фонетически пустой эксплетив pro. Это применяется ограниченно, в структурах с адвербиальными предикатами психического состояния на -о и с глаголом бывать и унаккузативным глаголом нравиться.

Данные эксплетивные субъекты свободно чередуются и не являются тематическими. Они занимают позицию SpecTP в конструкциях и требуют согласования в 3 л. ед. ч. среднего рода.

На основе данных НКРЯ мы посмотрели, с какой частотой встречается эксплетивное это и рro с имеющимися в моих примерах адвербиальными предикатами ${ }^{12}$.

\begin{tabular}{|l|l|l|}
\hline Адвербиальный предикат & эксплетивное это & pro \\
\hline удивительно & 4 & 96 \\
\hline приятно & 3 & 97 \\
\hline интересно & 1 & 99 \\
\hline любопытно & 0 & 100 \\
\hline странно & 5 & 95 \\
\hline
\end{tabular}

Как данные таблицы показывают, структуры с рro субъектом более распространенные с адвербиальными предикатами чем эксплетив.

Возникает вопрос о причине ограниченного появления эксплетивных субъектов. Явление по всей вероятности объясняется тем, что и адвербиальные предикаты, и само местоимение это являются новообразованиями в русском языке. Также их появление связано с преобразованием ЕРР свойств языка, то есть работает тенденция к выполнению SpесТР позиции в языке.

Данный анализ конечно надо расширять и на другие унаккузативные глаголы русского языка.

\section{Библиография}

АПРЕСЯН 1985: Апресян, Ю.Д., Синтаксические признаки лексем . // Russian Linguistics vol. 9. 280-315.

АПРЕСЯН 2014: Апресян В.Ю. (отв. ред.), Активный словарь русского языка. Т. 1 (А-Б) Москва.

БЕйлин 2011: Bailyn, J. F. The Syntax of Russian. Cambridge.

БИБЕРАУЕР 2012: Bieberauer, Т. \& van der Val, J.: Expletives Beyond English // Syntax of the World's Languages 5. Dubrovnik http://recosdtal.mml.cam.ac.uk/Publications/publications-folder/jw-handout-swl-5-expletives. 2016. 12.23.

12 Учитывались первые 100 результаты поиска в НКРЯ. Подобный анализ с бывать из-за разных побочных значений трудно составить. 
ВАЛГИНА 1991/2003: Валгина Н.С., Современный русский язык. Синтаксис. Москва. Высшая школа.

3OXEH 2002: Sochen, A. Expletives and Two Subject Positions in Russian FASL 10, Michigan Slavic Publications 223-248.

Из истории ненецкого народа 30-40-х годов XIX в. (Движение Ваули Пиеттомина) // http://www.vostlit.info/Texts/Dokumenty/Russ/XIX/1820-1840/Nenec_borba/text.htm

ДьЕРФИ 2016: Дьерфи Б., Развитие синтаксического статуса местоимений это и то // Studia Slavica Savariensia 1-2. 155-162.

ХАЗУТ, И 1994: Hazout, I. The pronoun "ze" and the syntax of sentential subjects // Lingua vol. 93/4. 265-282

МЕжЕВич, И. 2004: Mezhevich, I. On Russian 'Expletive' Éto and Post-Verbal Clauses // FASL 12 313-331 Michigan Slavic Publications

МитРенинА и др. 2012: Митренина, О.В., Романова Е.Е., Слюсарь, Н.А.: Введение в генеративную грамматику. УРСС. Москва.

ПАДучЕВА 2015: Падучева, Е. В., Глаголы быть, бывать: история и современность. Компьютерная лингвистика и интеллектуальные технологии: По материалам ежегодной Международной конференции Диалог (Москва, 27-30 мая 2015 г.). Основная программа конференции. (2015 г.)

ПеРлМУТтЕР-Мур 2002: Perlmutter, D. M. \& Moore, J. Language-Internal Explanation: The Distribution of Russian Impersonals// Language 78. 619-650.

СЛЮССАРь 2011: Slioussar, N.: Russian and the EPP requirement in the Tense domain // Lingua. Vol.121. Issue 14. 2048-2068.

ФРЕНКС 1995: Franks, S. Parameters of Slavic Morphosyntax. Oxford, OUP.

Хомский 1981: Chomsky, N. Lectures on Government and Binding: The Pisa Lectures. Holland. Foris Publications

Хомский 1995: Chomsky, N. The Minimalist Program. Cambridge, MA. The MIT Press.

ЦиММЕРЛИНГ 1997: Zimmerling, А.Семантика русских предикатов с финалью -о // Formale Slavistik. / U.Junghanns, G. Zybatow (hrsg). (Leipziger Schriften zur Kultur-, Literatur-, Sprach- und Uebersetzungswissenschaft, 7) Frankfurt-am-Main: Vervuert, P. 513-522.

ЦИМмЕРЛИнг 2009: Zimmerling, A. Dative subjects and semi-expletive pronouns in Russian // G. Zybatow, U. Junghanns, D. Lenertova, Biskup, P. eds. Studies in Formal Slavic Phonology, Morphology, Syntax, Semantics and Discourse Structure. Frankfurt-amMain - Berlin - Bruxelles - New York - Oxford - Wien pp. 253-268.

ЦИММЕРлинГ 2014: Zimmerling, А. Sententional Argument and Event Structure // Dialogue 2014 Computational linguistics and intellectual technologies issue 13. 710-727.

ШвЕДовА и др. 1980: Шведова, Н. Ю. Русская грамматика Том 2. Синтаксис. Москва. Издательство Наука.

ШурАНИ 2005: Surányi B. Ott ,there” in Hungarian and the theory of expletives.// https://s3.amazonaws.com/academia.edu.documents/33177611/Ottsquib.pdf?AWSAccessKeyId=AKIAIWOWYYGZ2Y53UL3A\&Expires $=1545260525 \&$ Signature $=6$ ISgKxPM1 cogE6b8Zk4fJdVnW6w\%3D\&response-content-disposition=inline\%3B\%20filename\%3DOtt_there_in_Hungarian_and the_theory_of.pdf

Beáta GYÖRFI

University of Debrecen Debrecen, Hungary

blazsenyka@yahoo.com 